\title{
AVALIAÇÃO DO PLANTIO HOMOGÊNEO DE MOGNO, Swietenia macrophylla King, EM COMPARAÇÃO COM O PLANTIO CONSORCIADO COM Eucalyptus urophylla S. T. Blake, APÓS 40 MESES DE IDADE ${ }^{1}$
}

\author{
Assis Brasil Guimarães Neto ${ }^{2}$, Jeanine Maria Felfili ${ }^{3}$, Gilson Fernandes da Silva ${ }^{3}$, Lucas Mazzei ${ }^{3}$, \\ Christopher William Fagg ${ }^{3}$ e Paulo Ernane Nogueira ${ }^{3}$
}

\begin{abstract}
RESUMO - Na Amazônia, plantios de mogno têm sido limitados por ataques de Hypsiphylla grandella Zeller. No entanto, plantios em áreas urbanas em Brasília vêm apresentando bom desenvolvimento. O objetivo deste trabalho foi observar o comportamento do mogno em plantios homogêneo e consorciado. Para isso foi instalado um experimento na Fazenda Água Limpa, da Universidade de Brasília (UnB), Distrito Federal, com dois tratamentos: plantio homogêneo e plantio misto com eucalipto. O primeiro consistiu no plantio homogêneo de mogno e o segundo, consorciado com eucalipto. Foram medidas as variáveis altura aos 7, 12, 15, 24, 28, 36 e 40 meses de idade e diâmetro aos 7, 24, 28, 36 e 40 meses. O delineamento utilizado foi inteiramente ao acaso, em esquema de parcelas subdivididas, sendo os tratamentos as parcelas e o tempo, as subparcelas. A altura média aos 40 meses do consórcio foi de 2,28 m e do homogêneo, de 3,45 m, sendo as alturas máximas, respectivamente, de 4,15 e 5,17 m. O diâmetro médio também foi maior no tratamento homogêneo do que no consórcio (4,08 e $6,92 \mathrm{~cm}$, respectivamente). A mortalidade situou-se em torno de $20 \%$, tanto no plantio homogêneo quanto no consorciado, não havendo diferenças significativas. O ataque das larvas de $\mathrm{H}$. grandella foi menor no plantio consorciado, indicando que o eucalipto serve como barreira física, diminuindo o ataque da praga, porém a competição de ambos ocasionou menor crescimento do mogno.
\end{abstract}

Palavras-chave: Amazônia, cerrado, mogno, Hypsiphylla grandella e silvicultura.

\section{EVALUATION OF MAHOGANY HOMOGENOUS STANDS, Swietenia macrophylla King, COMPARED TO MIXED STANDS WITH Eucalyptus urophylla S. T. Blake, 40 MONTHS AFTER PLANTING}

\begin{abstract}
In the Amazon, plantations of mahogany have been limited by attacks of Hypsiphylla grandella Zeller. On the other hand, urban plantings in Brasilia have developed well. The objective of this work was to observe the development of mahogany in homogenous or in mixed stands with eucalypts planted in the Água Limpa farm at the University of Brasilia - Federal District. The variables height, at 7, 12, 15, 24, 28, 36 and 40 months of age, and diameter, at 7, 24, 28, 36 and 40 months were measured. A split-plot entirely randomized design was used, the treatments being the plot and time the sub-plot. The average height of mahogan 40 months after planting in the mixed stands was of $2.28 \mathrm{~m}$, whereas in homogenous stands it was $3.45 \mathrm{~m}$ and the maximum heights recorded were $4.15 \mathrm{~m}$ and $5.17 \mathrm{~m}$ respectively. The average diameter was also larger in the homogenous stand, with $6.92 \mathrm{~cm}$ compared to $4.08 \mathrm{~cm}$ for the mixed stands. Mortality was around $20 \%$ under both conditions. Attacks by H. grandella larvae was less in mixed stands, indicating that the eucalypts may function as a barrier, reducing the attack.
\end{abstract}

Key-words: Amazonia, cerrado, mahogany, Hypsiphylla grandella, silviculture.

\footnotetext{
${ }^{1}$ Recebido em 08.07.2002 e aceito para publicação em 10.08.2004.

${ }^{2}$ Bolsista PIBIC-CNPq assisbr@bol.com.br

${ }^{3}$ Departamento de Engenharia Florestal, Universidade de Brasília, CEP:70919-970. C.P. 04357
} 


\section{INTRODUÇÃO}

A espécie Swietenia macrophylla King, mogno, da família das Meliáceas, tem em sua madeira valor muito grande devido às suas características físicas e anatômicas, constituindo-se em uma das principais fontes de madeira para exportação nos trópicos da América Latina.

Sua madeira é extremamente apreciada no fabrico de móveis, construção civil e acabamentos internos. O mogno tem as seguintes propriedades físicas: massa específica básica (peso seco em estufa/volume verde) de $0,45 \mathrm{~kg} / \mathrm{cm}^{3}$, contração tangencial de $4,1 \%$, contração radial de 3,0\% e contração volumétrica de 7,8\% (MELO et al., 1989).

Apesar de haver uma área de dispersão muito grande, com cerca de 150 milhões de hectares, a exploração seletiva pode afetar a integridade das populações. Existe uma clara tendência para a diminuição do número de árvores de mogno, especialmente de dimensões comerciais. Alguns países da América Central apresentam redução das populações originais. Em Guanacaste, Costa Rica, as populações de S. macrophylla têm diminuído consideravelmente, sendo indivíduos de 20-50 cm de DAP encontrados apenas em áreas protegidas (GERHARDT, 1996). Na Guatemala, a espécie está em perigo de extinção, assim como no Panamá, onde se encontra completamente exterminada em regiões acessíveis de fácil exploração (PATIÑO et al., 1996).

Embora estudos sobre silvicultura do mogno venham sendo conduzidos, não há ainda tecnologia para a implantação e condução de plantios homogêneos. Ataques freqüentes da lagarta de uma Lepidoptera, Hypsiphyla grandella Zeller, têm sido a barreira crítica para o sucesso do estabelecimento da espécie em plantios comerciais.

A larva da Lepidoptera alimenta-se da gema apical, destruindo-a. Sua ação produz deformação e bifurcação do tronco, atrasando consideravelmente o crescimento da planta afetada, chegando ocasionalmente, caso o ataque seja intenso, a causar sua morte. A bifurcação do tronco diminui seu valor comercial. Em viveiro, ataca mudas, tornando-as inviáveis para o plantio, havendo uma clara preferência pelo ponteiro apical, que exsuda goma e morre. No ápice dos ponteiros vivem em galerias longitudinais ou no interior de frutos. Um sinal de ataque da lagarta é a exsuda- ção de goma e serragem nos brotos (PEDROSAMACEDO, 1993). Tratamentos silviculturais, como eliminar plantas e frutos atacados, podar brotos infectados, utilizar espaçamentos amplos, plantios mistos e plantio fora da área de ocorrência natural da espécie podem servir como forma de controle ao ataque de H. grandella (PEDROSA - MACEDO, 1993), assim como de outros inimigos naturais.

O desenvolvimento do mogno no cerrado apresenta-se promissor. Jacinto (2001), avaliando grupos de árvores de $S$. macrophylla plantadas em ambiente urbano no Distrito Federal, no ano de 1963, encontrou uma altura média de 24,0 m e DAP igual a $64,5 \mathrm{~cm}$. Nas árvores plantadas no ano de 1984, o referido autor encontrou 19,4 m de altura média e 37,0 cm de DAP.

O plantio do mogno pode vir a agregar renda a pequenas propriedades. Se adotado um modelo que compreenda um mosaico de plantios em pequenas escalas e intercalados com outros usos do solo, pode-se reduzir a possibilidade de ataque da Lepidoptera. Esses plantios poderiam ser incorporados ao manejo da reserva legal das propriedades rurais, valorizando-as e levando os seus proprietários a protegê-las de incêndios e outras agressões em razão da perspectiva de melhor retorno econômico. O plantio de espécies nativas, mesmo que ex situ, contribui, também, para a manutenção da diversidade genética de espécies.

Este trabalho teve como objetivo avaliar:

a) A diferença no desenvolvimento em altura e diâmetro entre o plantio homogêneo de $S$. macrophylla e o plantio consorciado de $S$. macrophylla com Eucalyptus urophylla nos diferentes períodos estudados.

b) A diferença no número de indivíduos mortos entre o plantio homogêneo e o plantio consorciado, após 40 meses de idade.

c) A diferença no número de indivíduos atacados por Hypsiphyla grandella entre o plantio homogêneo e o plantio consorciado, após 40 meses de idade.

\section{MATERIAL E MÉTODOS}

\subsection{Descrição da área de estudos}

Este estudo foi implantado na área de silvicultura da Fazenda Água Limpa - FAL (15 50'58' S e 4754'11' W), de propriedade da Universidade de Brasília, no Distrito Federal, em dezembro de 1997. 
O clima da região corresponde ao tipo Cwa, da classificação de Köeppen - tropical de altitude (CODEPLAN, 1984), que apresenta duas estações bem distintas, uma chuvosa (novembro-abril) e outra seca (maio - outubro). A precipitação média é de $1.500 \mathrm{~mm}$ e a altitude, de $1.100 \mathrm{~m}$. A vegetação original na área de estudo é de cerrado sensu stricto sobre Latossolo Vermelho-Escuro. Essa condição é bem representativa das condições de solo da região do cerrado, representando 38,65\% dos solos do DF (HARIDASAN, 1993) e $46 \%$ do bioma Cerrado (REATTO et al., 1998).

\subsection{Preparo das mudas}

As mudas foram formadas a partir de sementes de $S$. macrophylla procedentes de árvores plantadas na Esplanada dos Ministérios há 37 anos pelo Departamento de Parques e Jardins, em Brasília (DF). A semadaura foi feita em sacos de polietileno ( $17 \times 25$ $\mathrm{cm}$ ), sob pleno sol, permanecendo no viveiro durante um ano. Na época seca, as mudas foram irrigadas duas vezes ao dia, durante a manhã e ao final da tarde. O substrato utilizado foi subsolo de cerrado, sem fertilização. As mudas levadas para o campo se encontravam sadias e em bom estado fitossanitário.

\subsection{Preparo do solo}

Na preparação do terreno foi utilizada uma grade com discos de $50 \mathrm{~cm}$ de diâmetro e logo após foram abertas covas com sulcador. A adubação foi feita em cada cova, utilizando-se $100 \mathrm{~g}$ de NPK na formulação 4-30-16, não havendo nenhum tipo de calagem.

O combate à formiga e aos cupins foi feito, antes do plantio, com formicida em pó, da marca MIREX.

\subsection{Coleta de dados}

Foram mensurados a altura das plantas e o diâmetro do coleto. Para as medições da altura, utilizou-se uma vara telescópica, e do diâmetro, um paquímetro digital. O diâmetro foi avaliado a $5 \mathrm{~cm}$ do solo e a altura, até a gema apical.

A observação de danos provocados por ataque de formigas, cupins e outros insetos foram efetuados semanalmente. Para o monitoramento do parâmetro altura foram realizadas medições nas respectivas idades de $7,12,15,18,24,28,36$ e 40 meses. Para o parâmetro diâmetro, efetuaram-se mensurações, nas idades de
7, 24, 28, 36 e 40 meses, respectivamente, sendo a última medida realizada no mês de abril de 2000 .

\subsection{Análise estatística}

Conforme proposto no objetivo do trabalho, pretendeu-se com o experimento verificar se houve diferenças no desenvolvimento de plantios homogêneos e consorciados de mogno. Para tanto, foram propostos dois tratamentos. $\mathrm{O}$ primeiro tratamento consistiu no plantio de 200 mudas de mogno com um espaçamento entre linhas de $3 \mathrm{~m}$ e entre plantas de $2 \mathrm{~m}$, enquanto o segundo foi implantado também com 200 mudas de mogno consorciadas com Eucalyptus urophylla S. T. Blake. O eucalipto foi plantado entre as linhas de $S$. macrophylla, fazendo com que aumentasse para $6 \mathrm{~m}$ a distância entre as linhas, continuando com 2 $m$ entre indivíduos. Devido a questões operacionais, os tratamentos foram divididos em quatro talhões com 50 repetições cada (croqui em anexo). Duas linhas foram deixadas como bordadura em volta de cada talhão, para evitar influências externas nas linhas extremas.

Os dados foram analisados segundo o Delineamento Inteiramente ao Acaso (DIC), em esquema de parcelas subdivididas, em que os tipos de povoamento constituíram as parcelas e os tempos, as subparcelas. Assim, tiveram-se como parcelas os tipos homogêneo e consorciado e como subparcelas, os tempos de $7,12,15,24,28,36$ e 40 meses, para a variável altura e os tempos de 7, 24, 28, 36 e 40 meses, para a variável diâmetro.

As análises de variância das variáveis foi feita, empregando-se o teste F em nível de 5\% de probabilidade. Para comparações entre os níveis das parcelas, empregou-se o teste de Tukey no nível de 5\% de probabilidade. Para avaliar a variação das variáveis em relação ao tempo, modelos de regressão foram ajustados. Para seleção do melhor modelo, tomaramse o teste $t$ de significância dos parâmetros, o coeficiente de determinação $\left(R^{2}\right)$ e o coeficiente de variação (CV). Nas análises de regressão das variáveis altura e diâmetro dos tipos em relação ao tempo, consideraram-se apenas modelos lineares, devido ao fato de o plantio se encontrar na fase juvenil de crescimento.

As mortalidades do plantio homogêneo de $S$. macrophylla e do plantio consorciado de $S$. macrophylla com E. urophylla foram comparadas através do teste Qui-quadrado em nível de 5\% de probabilidade. Essa

R. Árvore, Viçosa-MG, v.28, n.6, p.777-784, 2004 
comparação foi feita para o número total de indivíduos mortos ao final dos 40 meses de idade.

O número de indivíduos atacados por $H$. grandella no plantio homogêneo e no plantio consorciado foi comparado pelo teste de Qui-quadrado a 5\%, sendo amostrados todos os indivíduos que tinham sido atacados, pelo menos uma vez, até os 40 meses de idade.

\section{RESULTADOS E DISCUSSÃO}

\subsection{Desenvolvimento em altura}

A análise de variância da variável altura indicou haver interação significativa entre os tipos, plantio homogêneo de mogno e plantio consorciado de mogno com eucalipto, e o tempo (Quadro 1).

Para se analisarem os tipos dentro de cada tempo foi utilizado o teste de Tukey em nível de 5\% de probabilidade (Quadro 2), já para os tempos dentro de cada tipo foram ajustadas as equações de regressão (Figuras 1 e 2).

De acordo com o Quadro 2, pode-se observar que as alturas médias diferiram entre os tratamentos a partir dos 24 meses de idade. Verificou-se que há uma desaceleração no crescimento do plantio consorciado, provavelmente pela competição com o eucalipto, uma espécie de rápido crescimento. A diferença entre as médias dos indivíduos do tipo homogêneo em relação aos do consórcio foi de 1,17 m aos 40 meses (Quadro

Quadro 1 - Análise de variância da variável altura nos tipos de plantio homogêneo de $S$. macrophylla e plantio consorciado S. macrophylla $\mathrm{x}$ Eucalyptus urophylla e os tempos 7, 12, 15, 24, 28, 36 e 40 meses, na Fazenda Água Limpa, DF

Table 1-Analysis of variance for the average height of $S$. macrophylla plants grown in homogenous or in mixed stands with eucalypts, at 7, 12, 15, 24, 28, 36 and 40 months of age, in the Água Limpa Farm, DF

\begin{tabular}{lcccr}
\hline FV & GL & SQ & QM & F \\
\hline Tipo & 1 & 123,48 & 123,48 & $96,46^{*}$ \\
Erro (a) & 300 & 385,59 & 1,28 & \\
Tempo & 6 & $1.592,19$ & 265,36 & $1.984,08^{*}$ \\
Tipo x Tempo & 6 & 120,06 & 20,01 & $149,62^{*}$ \\
Erro (b) & 1800 & 240,74 & 0,133 & \\
\hline Total & 2113 & $2.462,08$ & 410,26 & \\
\hline
\end{tabular}

*significativo em nível de $5 \%$ de probabilidade, pelo teste "F".
2). Nessa ocasião, as alturas máximas foram de 5,17 $\mathrm{m}$ para o plantio homogêneo e $4,15 \mathrm{~m}$ no consórcio, e já se encontrava eucalipto com $10 \mathrm{~m}$ de altura.

Quadro 2 - Médias de alturas (m) nos tipos de plantio de S. macrophylla homogêneo e consorciado com eucalipto por idade (meses) na Fazenda Água Limpa, DF

Table 2-Average heights (m) of S. macrophylla, grown in homogenous or mixed stands with eucalypts sampled at different ages (months) in Água Limpa Farm, DF

\begin{tabular}{ccc}
\hline Idades (mês) & \multicolumn{2}{c}{ Tratamentos } \\
& Homogêneo & Consorciado \\
\hline 7 (jul) & $0,56_{\mathrm{a}}$ & $0,57_{\mathrm{a}}$ \\
12 (dez) & $0,98_{\mathrm{a}}$ & $0,999_{\mathrm{a}}$ \\
15 (mar) & $1,26_{\mathrm{a}}$ & $1,21_{\mathrm{a}}$ \\
24 (dez) & $1,59_{\mathrm{a}}$ & $1,29_{\mathrm{b}}$ \\
28 (abr) & $2,97_{\mathrm{a}}$ & $2,01_{\mathrm{b}}$ \\
36 (dez) & $3,27_{\mathrm{a}}$ & $2,34_{\mathrm{b}}$ \\
40 (abr) & $3,45_{\mathrm{a}}$ & $2,28_{\mathrm{b}}$ \\
\hline
\end{tabular}

Médias seguidas por uma mesma letra não diferem estatisticamente pelo Teste de Tukey em nível de 5\% de probabilidade.

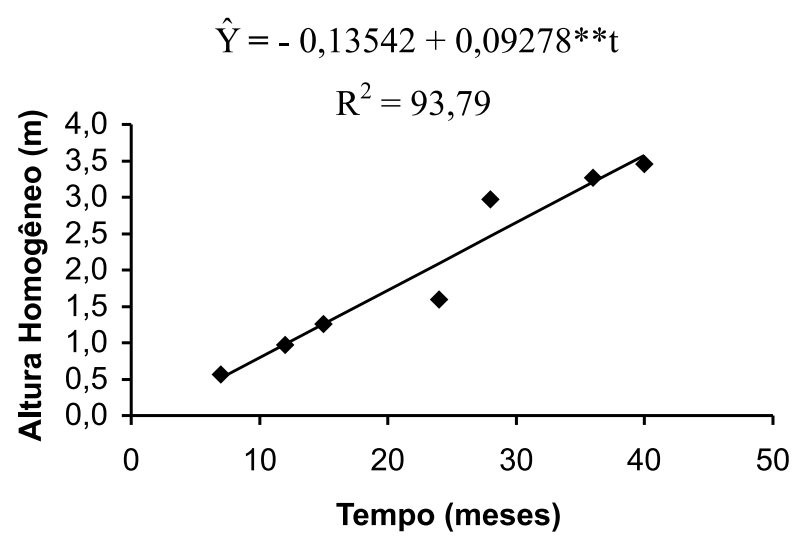

Figura 1 - Variações na altura em função do tempo, no plantio homogêneo de S. macrophylla na Fazenda Água Limpa, em que $(* *)$ representa a significância do parâmetro de regressão pelo teste t a $1 \%$ de probabilidade e $\mathrm{R}^{2}$ é igual ao coeficiente de determinação.

Figure 1-Height variations with time for the homogenous stand of S. macrophylla in Água Limpa Farm$D F$, where $(* *)$ represents the significance of the regression parameter by the t test at $1 \%$ probability and $R^{2}$ is equal to the determination coefficient. 


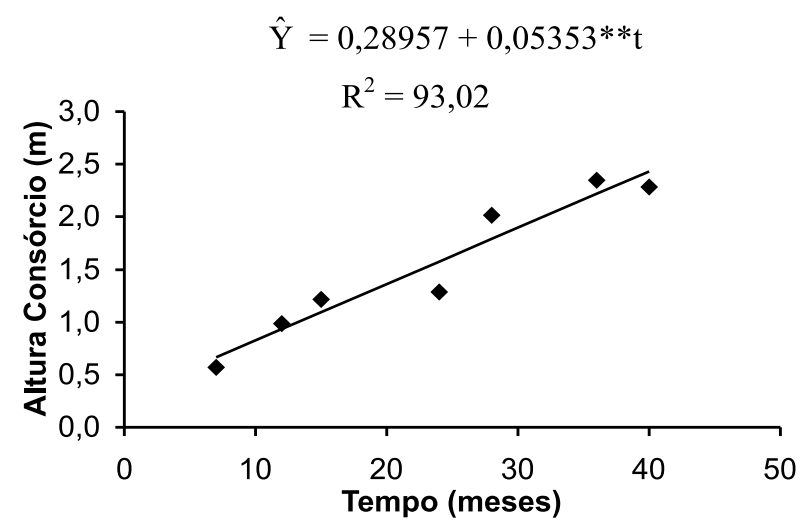

Figura 2 - Variações na altura em função do tempo, no plantio consorciado de S. macrophylla com Eucalyptus urophylla na Fazenda Água Limpa, em que (**) representa a significância do parâmetro de regressão pelo teste t a $1 \%$ de probabilidade e $\mathrm{R}^{2}$ é igual ao coeficiente de determinação.

Figure 2-Height variations with time for the mixed stands of S. macrophylla with Eucalyptus urophylla in Água Limpa Farm - DF, where (**) represents the significance of the regression parameter by the test at $1 \%$ probability and $R^{2}$ is equal to the determination coefficient.

De acordo com o Quadro 2, no plantio consorciado houve diminuição da média de altura dos indivíduos entre 36 e 40 meses de idade. Isso provavelmente ocorreu devido ao ataque da broca, que foi mais intenso nesse período. A larva da broca se alimenta da gema apical, destruindo-a. Esse ataque causa deformação e bifurcação no tronco, sendo necessária a poda do ramo, o que atrasa consideravelmente o crescimento da planta afetada (PEDROSA-MACEDO, 1993).

De acordo com as equações ajustadas, os incrementos em altura do período analisado foram de 9,28 $\mathrm{cm} / \mathrm{mês}$ e $5,35 \mathrm{~cm} / \mathrm{mês}$, nos tipos homogêneo e consorciado, respectivamente. Veríssimo e Grogan (1998) citaram incrementos médios anuais em altura, em plantios comerciais, de 0,66 até 1,63 m/ano. Com isso, o plantio homogêneo, com uma média estimada de $1,11 \mathrm{~m} /$ ano, é compatível com os resultados de outros estudos, como de Veríssimo e Grogan (1998), e o plantio consorciado, com 0,64 m/ano, está abaixo do normalmente encontrado. Como era esperado, o incremento foi menor no consórcio devido à competição do mogno com o eucalipto, que se deu principalmente a partir do segundo ano de implantação do experimento, e também pelo ataque da broca entre os 36 e 40 meses de idade, que foi muito intenso, por causa do final do período chuvoso. Contudo, não se deve esquecer de que no consórcio, apesar da redução do crescimento do mogno, há também o desenvolvimento do eucalipto.

\subsection{Desenvolvimento em diâmetro}

De acordo com o Quadro 3, pode-se observar que a interação entre os tipos de plantio (homogêneo e em consórcio) de mogno e os tempos foi significativa pelo teste "F" em nível de $5 \%$ de probabilidade.

Em todos os tempos considerados, as médias dos diâmetros nos tipos (homogêneo e não-homogêneo) diferiram estatisticamente, pelo teste de Tukey a 5\% de probabilidade, a partir de 24 meses de idade, assim como verificado nas alturas (Quadro 4). A provável competição entre o eucalipto e o mogno causou diminuição no crescimento do plantio consorciado. A diferença entre a média dos indivíduos do tipo homogêneo em relação aos do consórcio foi de $2,84 \mathrm{~cm}$ aos $40 \mathrm{me}$ ses, de acordo com o Quadro 4. Nessa ocasião, os diâmetros máximos foram de $9,6 \mathrm{~cm}$ no plantio homogêneo e $6,1 \mathrm{~cm}$ no consórcio.

As medições de diâmetro do coleto apresentaram oscilações entre os períodos, uma vez que, devido ao pequeno porte das plantas por ocasião do plantio, foi decidido fixar o ponto de medição a $5 \mathrm{~cm}$ do nível do solo.

Quadro 3 - Análise de variância da variável diâmetro, em que os tipos são homogêneo de S. macrophylla e consórcio de $S$. macrophylla e E. urophylla e os tempos, 7, 24, 28, 36 e 40 meses de idade, na Fazenda Água Limpa, DF

Table 3 - Analysis of variance for the average diameter of S. macrophylla in homogenous and mixed stands with eucalypts, at 7, 24, 28, 36, and 40 months of age, in Água Limpa Farm, DF

\begin{tabular}{lcccc}
\hline FV & GL & SQ & QM & F \\
\hline Tipo & 1 & 984,09 & 984,09 & $288,59^{*}$ \\
Erro (a) & 300 & $1.022,50$ & 3,41 & \\
Tempo & 4 & $2.269,31$ & 567,33 & $1.679,02^{*}$ \\
Tipo x Tempo & 4 & 427,85 & 106,96 & $316,56^{*}$ \\
Erro (b) & 1200 & 405,47 & 0,34 & \\
\hline Total & 1.509 & $5.109,22$ & $1.662,13$ & \\
\hline
\end{tabular}

significativo em nível de $5 \%$ de probabilidade, pelo teste "F". 
Quadro 4 - Médias dos diâmetros $(\mathrm{cm})$ nos tipos de plantio de S. macrophylla homogêneo e consorciado com eucalipto por idade (meses), na Fazenda Água Limpa, DF

Table 4-Average diameters ( $m$ ) of S. macrophylla homogenous and mixed stands with eucalypts at different ages (months), in Água Limpa Farm, DF

\begin{tabular}{ccc}
\hline Idade (mês) & \multicolumn{2}{c}{ Tratamento } \\
& Homogêneo & Consorciado \\
\hline 7 (jul.) & $2,177_{\mathrm{a}}$ & $2,12_{\mathrm{a}}$ \\
24 (dez.) & $4,32_{\mathrm{a}}$ & $3,64_{\mathrm{b}}$ \\
28 (abr.) & $6,20_{\mathrm{a}}$ & $4,10_{\mathrm{b}}$ \\
36 (dez.) & $6,30_{\mathrm{a}}$ & $3,89_{\mathrm{b}}$ \\
40 (abr.) & $6,92_{\mathrm{a}}$ & $4,08_{\mathrm{b}}$ \\
\hline
\end{tabular}

Médias seguidas por uma mesma letra não diferem estatisticamente pelo teste de Tukey em nível de 5\% de probabilidade dentro das datas.

O estudo do efeito do tempo em cada tipo de plantio foi feito por meio de análise de regressão. De acordo com as Figuras 3 e 4, pode-se observar que o modelo que melhor se ajustou foi o linear, baseado no teste t para significância dos parâmetros e no coeficiente de determinação $\left(\mathrm{R}^{2}\right)$. Provavelmente, isso ocorreu porque a cultura se encontrava numa fase inicial de crescimento, e, considerando que a tendência de crescimento se aproxima de uma curva sigmoidal, em curtos períodos de tempo, parte dessa curva pode ser representada satisfatoriamente por uma reta.

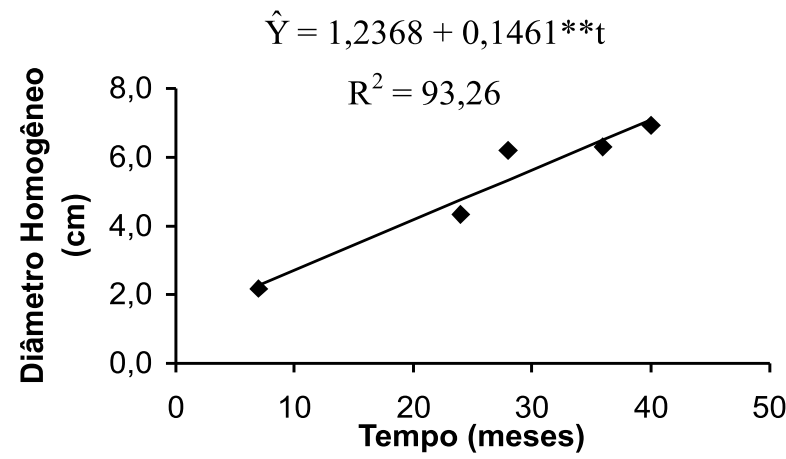

Figura 3 - Variações no diâmetro em função do tempo, no plantio homogêneo de S. macrophylla na Fazenda Água Limpa, em que (**) representa a significância pelo teste $\mathrm{t}$ a $1 \%$ de probabilidade e $\mathrm{R}^{2}$ é igual ao coeficiente de determinação.

Figure 3-Diameter variations by time for the homogenous stand of S. macrophylla in Água Limpa Farm - $D F$, where (**) represents the regression parameter significance by test at $1 \%$ probability and $R^{2}$ is equal to the determination coefficient.

R. Árvore, Viçosa-MG, v.28, n.6, p.777-784, 2004

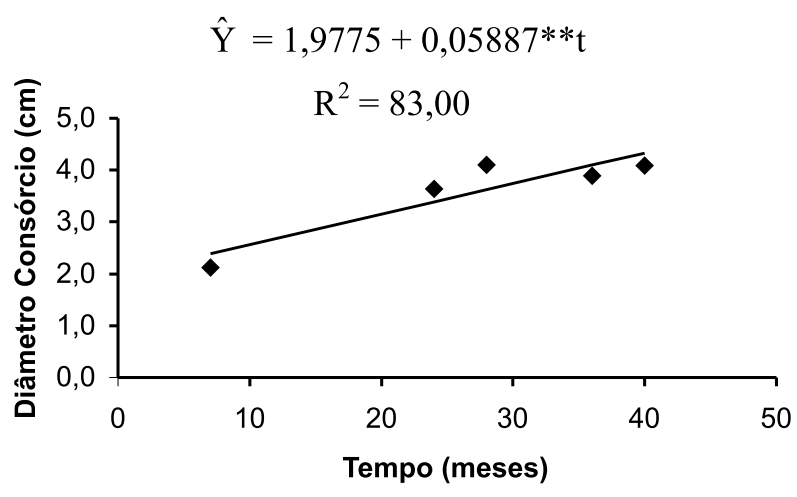

Figura 4 - Variações no diâmetro em função do tempo, no plantio consorciado de $S$. macrophylla com Eucalyptus urophylla na Fazenda Água Limpa em que $(* *)$ representa a significância pelo teste t a $1 \%$ de probabilidade e $\mathrm{R}^{2}$ é igual ao coeficiente de determinação.

Figure 4-Diameter variations with time for the mixed stand of S. macrophylla with Eucalyptus urophylla in Água Limpa Farm - DF, where (**) represents the significance of the regression parameter by test at $1 \%$ probability and $R^{2}$ is equal to the determination coefficient.

Observou-se também, de acordo com os coeficientes $\mathrm{b}_{1}$ das equações ajustadas (Figuras 3 e 4), que os incrementos estimados foram de $0,1461 \mathrm{~cm} / \mathrm{mês} \mathrm{e} 0,059$ $\mathrm{cm} / \mathrm{mês}$, nos tratamentos homogêneo e consorciado, respectivamente. Veríssimo et al. (1995) e Veríssimo e Grogan (1998), revisando plantios comerciais em todo o mundo, onde os incrementos médios anuais de diâmetro variam de 0,74 a 3,0 cm de incremento por ano, o que mostra, assim como na altura, que o plantio homogêneo situa-se num patamar intermediário de incremento, com o aumento estimado de $1,75 \mathrm{~cm} /$ ano e o plantio consorciado um pouco abaixo, com $0,71 \mathrm{~cm} /$ ano. $\mathrm{O}$ desenvolvimento em diâmetro foi melhor no tratamento homogêneo, o que evidencia o efeito da competição no tratamento consorciado de $S$. macrophylla com E. urophylla.

\subsection{Mortalidade}

No plantio homogêneo de S. macrophylla, 44 indivíduos (22\%) chegaram até a idade de 12 meses, ressaltando-se que $42(21 \%)$ morreram até os sete meses e dois (1\%) no período de 7 a 12 meses de idade. O ataque de formigas logo após o plantio foi a principal causa de mortalidade. No plantio consorciado com E. urophylla, o número de mortes foi de 32 plantas 
(16\%), todas ocorridas até sete meses de idade. Pelo teste Qui-quadrado em nível de 5\% de probabilidade $\left(\chi_{\mathrm{o}}^{2}=2,34\right.$ e $\left.\chi_{\mathrm{c}}^{2}=3,84\right)$, não houve diferença de mortalidade entre os dois tratamentos propostos.

\subsection{Ataque de Hypsiphylla grandella}

$\mathrm{O}$ ataque da broca foi mais intenso a partir do final das chuvas e por todo o período de estiagem, entre os meses de abril e setembro. $\mathrm{O}$ ataque foi controlado através da poda dos ramos infectados e da eliminação das larvas da Lepidoptera.

O número de indivíduos atacados diferiu estatisticamente pelo teste Qui-quadrado em nível de 5\% de probabilidade $\left(\chi^{2}=67,31\right.$ e $\left.\chi^{2}{ }_{\mathrm{c}}=3,84\right)$. No tratamento homogêneo, o ataque ocorreu em 111 indivíduos, $71 \%$ do total de plantas vivas. Já no consórcio o ataque se deu em 43 indivíduos, perfazendo $25,6 \%$ deles, indicando que o tratamento consorciado foi mais eficiente no combate ao ataque da praga até o período de 40 meses. Yamazaki et al. (1990) afirmaram que o crescimento sem ataques intensivos de $H$. grandella é possibilitado quando o plantio de $S$. macrophylla é feito em baixo do dossel da mata. Marques e Brieza (1992) relataram que o consórcio de mogno com banana apresentou uma taxa de ataque de $21 \%$ aos 24 meses. Essa baixa ocorrência pode ser explicada possivelmente pela barreira lateral proporcionada pelo bananal. Barros e Brandi (1975) verificaram um ataque agressivo da lagarta, em que $100 \%$ das mudas foram atacadas até os 24 meses de idade. No plantio consorciado de $S$. macrophylla com E. urophylla, o eucalipto funcionou como uma barreira física, evitando que a praga atacasse as árvores de mogno. Contudo, devem-se continuar as observações. Sousa et al. (1996), em trabalho realizado com mogno consorciado com ingá, citaram que a broca atacou indivíduos em alturas superiores a $6 \mathrm{~m}$.

Esses resultados indicam que, apesar de o tratamento homogêneo apresentar melhores resultados em termos de desenvolvimento das variáveis altura e diâmetro, o consórcio torna-se mais eficiente no combate a $H$. grandella até os 40 meses de idade.

Quando diminui o ataque, diminui também o número de indivíduos que serão eliminados, pois o ataque provoca bifurcação na altura em que ele ocorre, reduzindo a altura comercial da planta. Ao diminuir essa altura, as toras produzidas perdem consideravelmente seu valor. No entanto, se a poda do ramo atacado for feita logo após o ataque para evitar uma brotação em massa dos indivíduos, a planta retoma a dominância apical.

As plantas no tratamento homogêneo desenvolveram-se melhor que no plantio consorciado, pois, mesmo quando atacadas pela Hipsiphylla, retomam sua dominância apical se podada após o ataque, no entanto a taxa de ataque foi menor no consórcio. Portanto, estudos econômicos devem ser realizados para que seja verificada a melhor alternativa: se plantio homogêneo ou em consórcio. Deve-se considerar que no tratamento consorciado, além do mogno, o eucalipto é uma fonte de renda. A prática de desbaste do eucalipto ao verificar-se a desaceleração do crescimento do mogno e o uso de espécies nativas de crescimento rápido como angicos, acácias e guapuruvus no consórcio parecem ser desejáveis.

\section{CONCLUSÃO}

O plantio homogêneo de $S$. macrophylla apresentou melhores resultados nas médias de altura e de diâmetro em relação ao plantio consorciado de $S$. macrophylla com $E$. urophylla, com a diferença chegando a $1,17 \mathrm{~m}$ na altura e $2,84 \mathrm{~cm}$ no diâmetro. As alturas e diâmetros máximos atingiram no plantio homogêneo, aos 40 meses, 5,17 m e 9,6 cm e no consórcio, 4,15 m e $6,1 \mathrm{~cm}$, respectivamente.

A competição entre o mogno e o eucalipto foi evidenciada a partir de 24 meses de idade, quando houve desaceleração no crescimento do mogno devido ao desenvolvimento do eucalipto, que foi bem maior.

Em relação à mortalidade, não houve diferenças significativas entre os dois tratamentos, situando-se na faixa de $20 \%$. No entanto, recomenda-se o combate a formigas, principalmente nos primeiros 12 meses.

$\mathrm{O}$ ataque da $H$. grandella foi menor no tratamento consorciado, o que indica que o eucalipto funciona como uma barreira física, diminuindo o ataque da broca, evidenciano, assim, o plantio consociado como uma boa alternativa ao combate a esta praga.

\section{AGRADECIMENTOS}

Ao CNPq-PRONEX-2 e PIBIC e ao Newton e Florisvaldo, pelo apoio em viveiro e campo, e ao Geraldo pelo auxílio na coleta de dados.

R. Árvore, Viçosa-MG, v.28, n.6, p.777-784, 2004 


\section{REFERÊNCIAS BIBLIOGRÁFICAS}

BARROS, N.F.; BRANDI, R. M. Observações sobre a ocorrência de ataque de Hypsipylla em plantas de mogno, na região de Viçosa, MG. Brasil Florestal, v.6 n.24, p. 22-25, 1975.

CODEPLAN. Atlas do Distrito Federal. Brasília: 1984. 79p.

GERHARDT, K. Germination and development of sown mahogany (Swietenia macrophylla King) in secondary dry forest habitats in Costa Rica.

Journal of Tropical Ecology, v.12, p.275289, 1996

HARIDASAN, M. Solos. In: PINTO, M.N. (Org.). Cerrado, caracterização, ocupação e perspectivas. Brasília: Universidade de Brasília, 1993.681p.

JACINTO, J. M. M. Análise silvicultural urbana de seis espécies florestais utilizadas na arborização de Brasília. 2001. 55f. Dissertação (Mestrado em Engenharia Florestal) - Universidade de Brasília, Brasília, 2001.

MARQUES, L. C. T.; BRIEZA JUNIOR, S. Sistemas agroflorestais na Amazônia Oriental: Aspectos técnicos e econômicos. In: ENCONTRO BRASILEIRO DE ECONOMIA E PLANEJAMENTO FLORESTAL, 2., 1992, Curitiba. Anais ... Curitiba: 1992. p.37-62.

MELO, J. E.; CARVALHO, G. M.; MARTINS, V. A. Espécies de madeiras substitutas do mogno. Manaus: IBAMA, 1989. 16p. (Série Técnica, 6).
PATIÑO, V. F. et al. Recursos genéticos de especies de la familia Meliaceae en los neotrópicos: prioridades para acciones cordinadas. Roma: FAO, 1996. 120p.

PEDROS A-MACEDO, J. H. Manual de pragas em florestas. Viçosa, MG: Folha Viçosa, 1993. v.2. 112p.

REATTO, A.; CORREIA, J.R.; \& SPERA, S.T. Solos do Bioma cerrado. In: SANO, S. M.; ALMEIDA, S. P. (Eds.). Cerrado: ambiente e flora. Planaltina: EMBRAPA-CPAC, 1998. p. 47-86.

SOUSA, S. G. A. et al. Comportamento do Mogno (Swietenia macrophylla) em sistemas agroflorestais na Amazônia Ocidental. In: SIMPÓSIO INTERNACIONAL DE ECOSSISTEMAS FLORESTAIS (FOREST 96), 4., 1996, Belo Horizonte. Anais ... Belo Horizonte: 1996. p.183-184.

VERÍSSIMO, A. et al. Extraction of high-value natural resource in Amazônia: The case of Mahogany. Forest Ecology and Management, v.72, p.39-60, 1995.

VERÍSSIMO, A.; GROGAN, J. Synthesis of mahogany natural history and management in the American tropics. Manaus: Instituto do Homem e Meio Ambiente da Amazônia, 1998. (Informativo Report 02-98).

YAMAZAKI, S. et al. Ecology of Hypsiphyla grandella and its seasonal changes in population density in Peruvian Amazon Forest. JARQ, v.24, p.149-155, 1990. 